\title{
Evaluation of the anticancer activities of two fungal polycyclic ethanones, alternethanoxins $A$ and $B$, and two of their derivatives
}

\author{
MARINA BURY ${ }^{1}$, BIANCAVALERIA PUNZO ${ }^{4}$, ALEXANDER BERESTETSKIY ${ }^{5}$, BENJAMIN LALLEMAND ${ }^{2}$, \\ JACQUES DUBOIS $^{2}$, FLORENCE LEFRANC ${ }^{1,3}$, VÉRONIQUE MATHIEU ${ }^{1}$, \\ ANNA ANDOLFI $^{4}$, ROBERT KISS $^{1}$ and ANTONIO EVIDENTE ${ }^{4}$ \\ ${ }^{1}$ Laboratoire de Toxicologie, ${ }^{2}$ Laboratoire de Chimie BioAnalytique, Toxicologie et Chimie Physique Appliquée, \\ Institut de Pharmacie, ${ }^{3}$ Service de Neurochirurgie, Hôpital Erasme, Université Libre de Bruxelles, Brussels, \\ Belgium; ${ }^{4}$ Dipartimento di Scienze, del Suolo, della Pianta, dell'Ambiente e delle Produzioni Animali, \\ Università di Napoli Federico II, Portici, Italy; ${ }^{5}$ All-Russian Institute of Plant Protection, \\ Russian Academy of Agricultural Science, Pushkin, Saint Petersburg 196608, Russia
}

Received June 16, 2010; Accepted August 2, 2010

DOI: 10.3892/ijo_00000842

\begin{abstract}
Alternethanoxins A (1) and B (2) are fungal phytotoxins that are produced by Alternaria sonchi and have been recently characterized as new polycyclic ethanones. Triacetyl (3) and dimethyl (4) derivatives of compound $\mathbf{1}$ were evaluated together with alternethanoxins for their in vitro growth inhibitory activities in five human and one mouse cancer cell lines in comparison to the reference compound temozolomide (TMZ). Compounds 1-4 and TMZ displayed similar growth inhibitory activities, and these anticancer activities were equivalent in cancer cell lines that display certain levels of resistance to pro-apoptotic stimuli and those that are sensitive to pro-apoptotic stimuli. Of the six cancer cell lines under study, the human esophageal cancer cell line OE21 was the most sensitive to the four polycyclic ethanones. Computerassisted phase-contrast microscopy (quantitative videomicroscopy) revealed that compounds $\mathbf{1 , 2}$ and $\mathbf{4}$ displayed cytostatic rather than cytotoxic growth inhibitory effects, while compound $\mathbf{3}$ appeared to have cytotoxic effects. Thus, this study creates a stimulus for further structure-activity investigations with respect to the anticancer activities of compounds belonging to the alternethanoxin group. The observed toxicity does not seem to be affected by the stereochemistry of C- 6 of the B ring, the presence of a hydroxy group at $\mathrm{C}-1$ or the presence of a furan ring joining rings $\mathrm{A}$ and $\mathrm{C}$ in alternethanoxin $\mathrm{B}$. The anticancer activity (cytostatic versus cytotoxic) of this type of compound could be affected by the chemical moieties present at the hydroxy groups at C-4
\end{abstract}

Correspondence to: Dr Robert Kiss, Laboratoire de Toxicologie, Institut de Pharmacie, Université Libre de Bruxelles, Campus de la Plaine, Boulevard du Triomphe, CP205/1, 1050 Bruxelles, Belgique E-mail: rkiss@ulb.ac.be

Key words: alternethanoxins, polycyclic ethanones, fungal phytotoxins, in vitro anticancer activity and C-6, as was observed for the cytostatic and cytotoxic activities of derivatives $\mathbf{4}$ and 3 , respectively.

\section{Introduction}

Phytopathogenic fungi are involved in several plant diseases; thus, their study is of critical importance. Considering the economic importance of many agrarian crops, several studies have attempted to understand the role of bioactive microbial metabolites in the pathogenic process. The chemical nature of these toxins ranges from low-molecular-weight compounds, such as all classes of terpenes, chromanones, butenolides, pyrones, macrolides, aromatic derivatives and amino acids, to high-molecular-weight compounds, such as proteins, glycoproteins and polysaccharides. As a result, many new phytotoxins have been reported (1-8). Phytotoxins, isolated from fungi that are pathogenic for weedy plants, are an important tool to realize new strategies for the control of plant infestations. Plants that infest economically important crops are another important problem, as they cause marked losses in crop production $(7,9,10)$. The original structures of several of these metabolites and the results of studies on their structure/activity relationships and the modes of action of some fungicides and phytotoxins (4-10) prompted us to investigate whether fungal metabolites belonging to the polycyclic ethanones (alternethanoxins) could display anticancer activities in vitro.

We used one mouse and five human cancer cell lines and the MTT colorimetric assay (11-14) to determine the in vitro $\mathrm{IC}_{50}$ growth inhibitory concentrations of alternethanoxins A (1) and B (2), two fungal phytotoxins produced by Alternaria sonchi and recently characterized as new polycyclic ethanones (15), and triacetyl (3) and dimethyl (4) derivatives of compound $\mathbf{1}$. We compared the in vitro anticancer activity of compounds 1, 2, 3 and 4 to the activities associated with the reference compound temozolomide (TMZ), which is used to treat cancers that display detectable levels of resistance to pro-apoptotic stimuli, including glioblastomas $(16,17)$ and, in some cases, melanomas $(16,18)$. 


\section{Materials and methods}

Fungal culture filtrates. The fungus Alternaria sonchi Davis was isolated from diseased leaves of Sonchus arvensis, and a monoconidial isolate (S-102) was deposited into the culture collection of the All-Russian Research Institute of Plant Protection, Pushkin, Saint Petersburg, Russia. The isolate was maintained in sterile tubes containing potato-dextrose agar.

Fungal metabolites and their derivatives. A. sonchi was grown on autoclaved pearl barley in ten 1000-ml Erlenmeyer flasks in the dark for 21 days, as reported previously (15). The solid culture $(100 \mathrm{~g})$ was dried and extracted according to a previously published protocol (19) with minor modifications. The organic extract was purified using a combination of silica gel preparative TLC to yield alternethanoxins A and B (1 and 2,51 and $2.2 \mathrm{mg}$, respectively) as a homogeneous yellow and amorphous solid, respectively, as reported previously (15). Alternethanoxin A was converted to the corresponding triacetyl- and dimethyl ether derivatives ( $\mathbf{3}$ and $\mathbf{4}$, respectively) through a reaction with acetic anhydride and pyridine and an ethereal solution of diazomethane, respectively, according to recently reported protocols (15).

Determining $I C_{50}$ in vitro growth inhibition concentrations. The overall growth levels of the human cancer cell lines were determined using the colorimetric MTT (3-[4,5-dimethylthiazol-2yl])-diphenyltetrazolium bromide, Sigma, Belgium) assay (11-14). Briefly, cell lines were incubated for $24 \mathrm{~h}$ in 96-microwell plates (at concentrations of 10,000-40,000 cells $/ \mathrm{ml}$ culture medium depending on the cell type) to ensure adequate plating prior to cell growth determinations. The assessment of cell population growth using the MTT colorimetric assay is based on the capability of living cells to reduce the yellow product MTT (3-(4,5)-dimethylthiazol-2-yl)-2,5diphenyltetrazolium bromide) to a blue product, formazan, by a reduction reaction in the mitochondria. The number of living cells after $72 \mathrm{~h}$ of culture in the presence (or absence; control) of the various compounds was directly proportional to the intensity of the blue color, which was measured quantitatively by spectrophotometry using a Bio-Rad Model 680XR (Bio-Rad, Nazareth, Belgium) at a 570-nm wavelength (with a reference wavelength of $630 \mathrm{~nm}$ ). Each experimental condition was run in sextuplicate (11-14).

We used one mouse and five human cancer cell lines that were obtained from the European Collection of Cell Culture (ECACC, Salisbury, UK), the American Type Culture Collection (ATCC, Manassas, VA, USA) and the Deutsche Sammlung von Mikroorganismen und Zellkulturen, (DSMZ, Braunschweig, Germany). The human cancer cell lines included the esophageal cancer line OE21 (ECACC code 96062201), the non-small cell lung cancer (NSCLC) line A549 (DSMZ code ACC107), the melanoma line SKMEL-28 (ATCC code HTB-72), the oligodendroglioma line Hs683 (ATCC code HTB-138) and the glioblastoma line U373 (ECACC code 89081403), while the mouse cancer cell line is the melanoma line B16F10 (ATCC code CRL-6475). The six cancer cell lines under study were cultured in RPMI medium (Invitrogen, Merelbeke, Belgium) supplemented with $10 \%$ heat-inactivated fetal calf serum, $4 \mathrm{mM}$ glutamine, $100 \mu \mathrm{g} / \mathrm{ml}$ gentamycin and penicillin-streptomycin $(200 \mathrm{U} / \mathrm{ml}$ and $200 \mu \mathrm{g} / \mathrm{ml}$, respectively) (Invitrogen). Temozolomide (TMZ; Schering Plough, Brussels, Belgium) was used as a reference compound.

Computer-assisted phase-contrast microscopy (quantitative videomicroscopy). The direct visualization of the effects of alternethanoxins A and B and their derivatives on OE21 cell proliferation and migration was carried out with computerassisted phase contrast microscopy (quantitative videomicroscopy), as detailed elsewhere $(20,21)$. OE21 cells were monitored for $72 \mathrm{~h}$ in the absence (control) or presence of the four compounds at their $\mathrm{IC}_{50}$ growth inhibitory concentrations (as calculated using the MTT assay). Movies were created from the obtained time-lapse image sequences, which enabled a detailed screen for cell viability to determine whether the compounds induced cytostatic or cytotoxic effects (22). All experimental conditions were performed in triplicate.

\section{Results and Discussion}

Alternaria sonchi, which has recently been proposed as a possible biocontrol agent of Sonchus arvensis, commonly called sowthistle and considered an important weed in Europe and North America, as it infests many habitats, including cultivated fields, showed to produce phytotoxins when grown in solid cultures (15). The two toxins, alternethanoxin A (1) and B (2), were characterized as two polycyclic ethanones containing a benzochromen moiety (15). Compound $\mathbf{2}$ differs from compound $\mathbf{1}$ in the inverted configuration at C-6 and the presence of a furan ring joining rings $\mathrm{A}$ and $\mathrm{C}$ (Fig. 1). The structure of compound $\mathbf{1}$ was confirmed by preparing its triacetyl (3) and dimethyl ether (4) derivatives (15). Compounds $\mathbf{1}$ and $\mathbf{2}$ did not demonstrate any antimicrobial activity (15). The ethanone compounds that were most similar to alternethanoxin A appeared to be the acetophenones, namely cynandiones A-D, cynanchone and analogs, which were isolated from the root of different Cynanchum plant species and show potential pharmacological applications, such as growth inhibitory activity against T-24 tumor cells (23).

The present study deals with the characterization of the in vitro anticancer properties of compounds $\mathbf{1 , 2 , 3}$ and 4. We adopted an in vitro pharmacological strategy that was similar to the one recently used to characterize the in vitro anticancer activities of various fungal metabolites (24). We first determined the $\mathrm{IC}_{50}$ in vitro growth inhibitory concentrations of these compounds using an MTT colorimetric assay in six distinct cancer cell lines, including four cancer cell lines that displayed various levels of resistance to pro-apoptotic stimuli and two cancer cell lines with high sensitivity to pro-apoptotic stimuli. The four cell lines that displayed detectable levels of resistance to pro-apoptotic stimuli included the human glioblastoma line U373 (17,25), the NSCLC line A549 (26), the melanoma line SKMEL-28 (27) and the esophageal cancer line OE21 (22). The two cell lines that were sensitive to pro-apoptotic stimuli were the human oligodendroglioma line Hs683 (28) and the mouse melanoma line B16F10 $(18,27)$. The data reported in Table I indicate that the $\mathrm{IC}_{50}$ values for compounds 1, 2, 3 and 4 ranged between approximately 


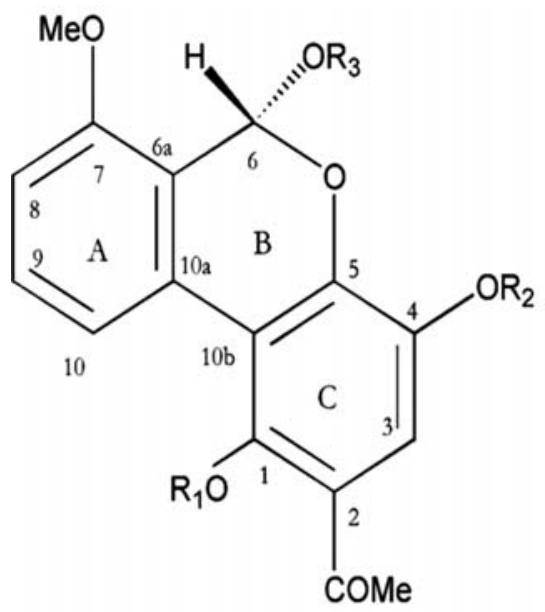

$1 \mathrm{R}_{1}=\mathrm{R}_{2}=\mathrm{R}_{3}=\mathrm{H}$

$3 \mathrm{R}_{1}=\mathrm{R}_{2}=\mathrm{R}_{3}=\mathrm{Ac}$

$4 \mathrm{R}_{1}=\mathrm{H}, \mathrm{R}_{2}=\mathrm{R}_{3}=\mathrm{Me}$

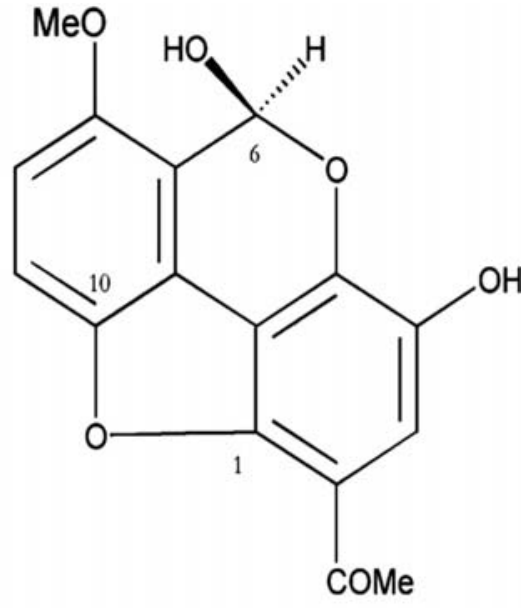

2

Figure 1. Chemical structure of alternethanoxins A (1) and B (2) and two derivatives of alternethanoxin A (3 and 4 ).

Table I. Determination of the in vitro $\mathrm{IC}_{50}$ growth inhibitory concentrations of four polycyclic ethanones (1-4; see Fig. 1) and the reference compound temozolomide (TMZ).

\begin{tabular}{lcccccc}
\hline & \multicolumn{5}{c}{$\mathrm{IC}_{50}$ in vitro growth inhibitory concentrations $(\mu \mathrm{M})($ mean \pm SEM values) } \\
\cline { 2 - 6 } Compounds & B16F10 & SKMEL28 & Hs683 & U373 & A549 & OE21 \\
\hline $\mathbf{1}$ & $91 \pm 3$ & $>100$ & $>100$ & $>100$ & $>100$ & $62 \pm 5$ \\
$\mathbf{2}$ & $>100$ & $>100$ & $71 \pm 8$ & $>100$ & $80 \pm 10$ & $64 \pm 3$ \\
$\mathbf{3}$ & $>100$ & $>100$ & $>100$ & $>100$ & $>100$ & $81 \pm 6$ \\
$\mathbf{4}$ & $72 \pm 8$ & $>100$ & $>100$ & $>100$ & $>100$ & $54 \pm 8$ \\
TMZ & $49 \pm 5$ & $>100$ & $>100$ & $>100$ & $>100$ & $52 \pm 2$ \\
\hline
\end{tabular}

The six cancer cell lines under study include the mouse melanoma B16F10 and the human melanoma SKMEL28, oligodendroglioma Hs683, glioblastoma U373, non-small cell lung cancer (NSCLC) A549 and esophageal OE21 cancer cell lines.

50 and $>100 \mu \mathrm{M}$ and that the four cancer cell lines that displayed detectable levels of resistance to pro-apoptotic stimuli were no more resistant to the anticancer effects induced by compounds 1-4 than were the cell lines that were sensitive to pro-apoptotic stimuli. In fact, one of the cell lines that were resistant to pro-apoptotic stimuli (22), OE21, also displayed the highest sensitivity to the growth inhibitory effects of compounds 1-4 (Table I). We were not able to obtain sufficient quantities of compounds 1-4 to accurately determine their $\mathrm{IC}_{50}$ growth inhibitory concentrations for concentrations $>100 \mu \mathrm{M}$ in each of the six cancer cell lines (Table I). Therefore, in Fig. 2, we report the percentages of cancer cells in each of the six lines that resisted $100 \mu \mathrm{M}$ concentrations of compounds 1-4 during three days of culture in the presence or absence (control condition $=100 \%$ ) of each compound. Fig. 2 reveals that compounds 1-4 induced growth inhibition at $100 \mu \mathrm{M}$ ranging from $18 \%$ (compound $\mathbf{4}$ in U373 cells; $\mathrm{p}<0.05$ compared to control) to $80 \%$ (compound 2 in OE21 cells; $\mathrm{p}<0.001$ compared to control). Altogether, these data strongly suggest that an alternethanoxin backbone could be used to produce original derivatives that are intended to combat cancers that resist pro-apoptotic stimuli because more than $80 \%$ of the chemotherapeutics in use today to combat cancers are pro-apoptotic agents (29), but numerous cancer types are naturally resistant to apoptosis, including gliomas (16,30), melanomas (31), pancreatic cancers (32), non-small cell lung cancers (33), esophageal cancers (34) and metastatic cancers $(35,36)$. It is therefore mandatory to identify novel therapeutics that kill cancer cells while resisting apoptosis.

The growth inhibitory activities for the compounds under study appeared to be similar to those observed for temozolomide in the six studied cancer cell lines. Temozolomide is an alkylating agent that contributes therapeutic benefits to glioblastoma patients (16) and in the experimental B16F10 melanoma model, in which TMZ appeared to be more efficient than cisplatin and as efficient as taxol, irinotecan and adriamycin (18). As indicated previously, glioblastomas 
$\square$ Alternethanoxin A (1) $\quad \square$ Triacetylalternethanoxin (3)
$\square$ Alternethanoxin B (2) $\quad$ Alternethanoxin A dimethyl-ether (4)

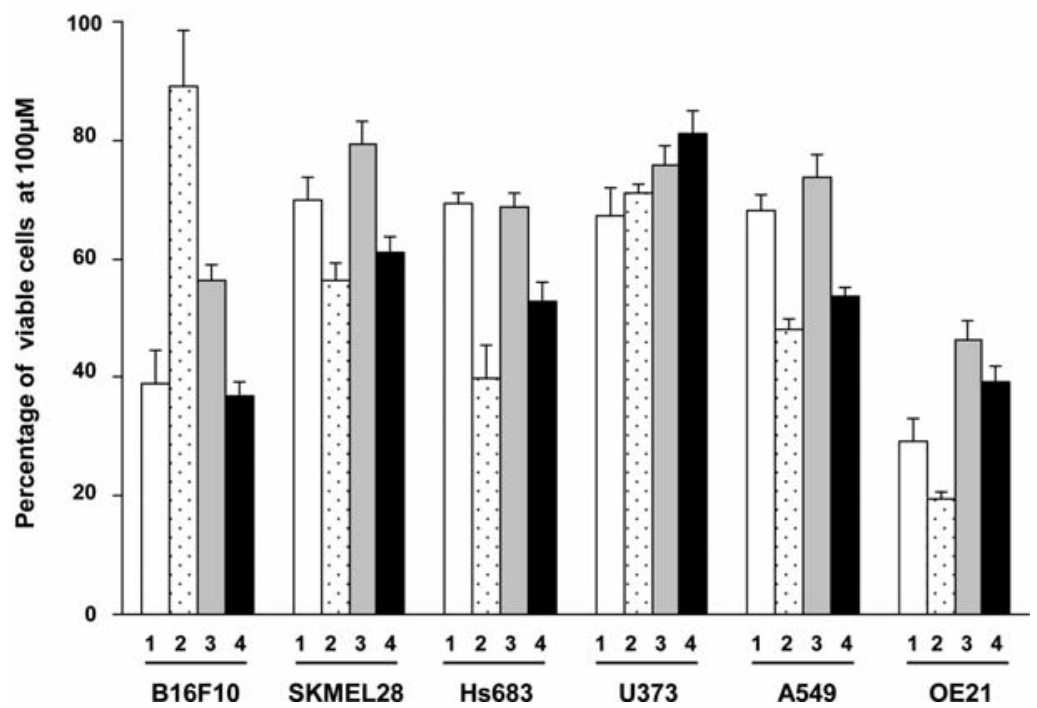

Figure 2. Determination (via MTT colorimetric assay) of the percentages of cancer cells that resist $100 \mu \mathrm{M}$ treatments of compounds 1-4 for $72 \mathrm{~h}$. Each experimental condition was run in sextuplicate, and data are presented as mean \pm SEM values.

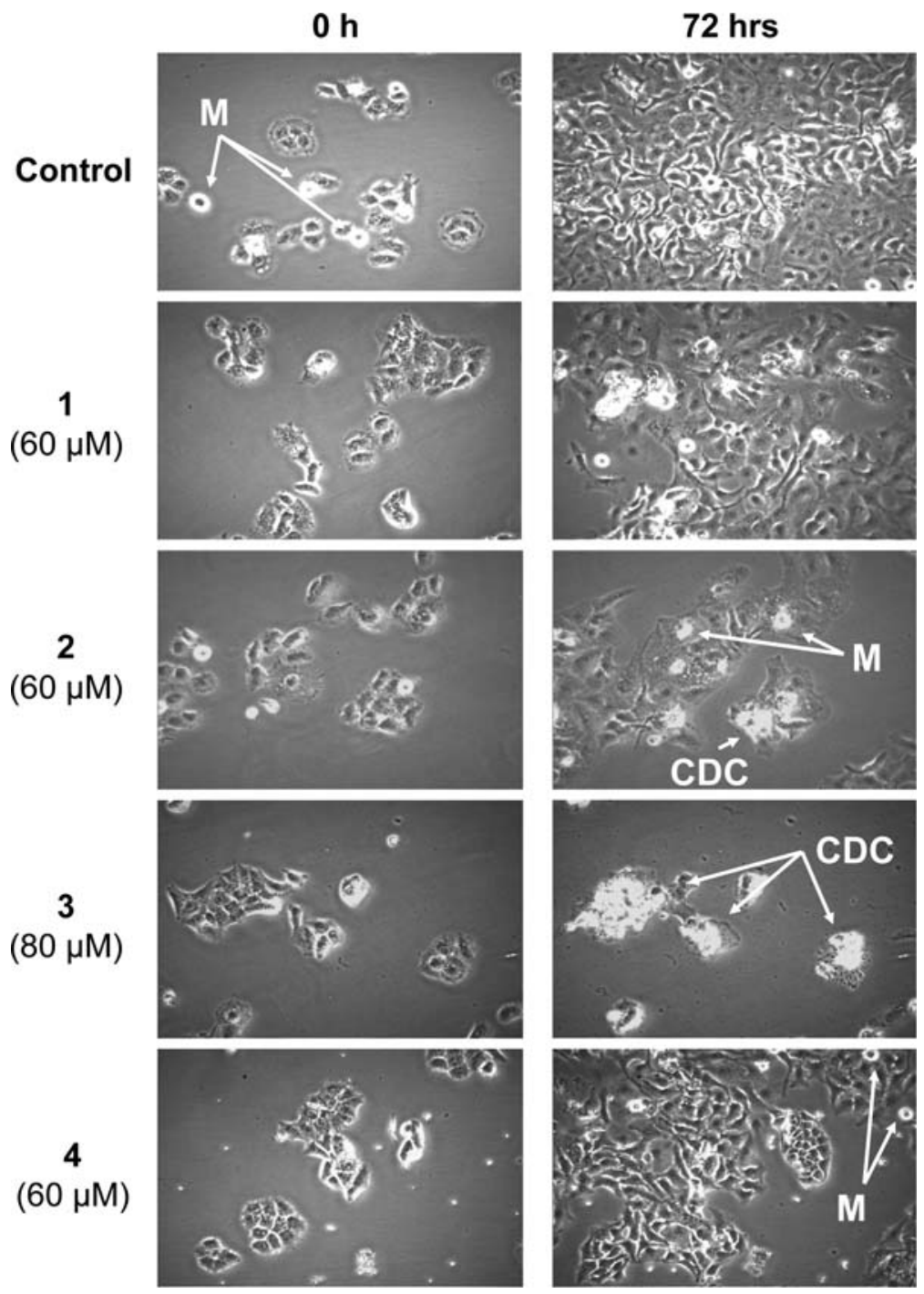

Figure 3. Morphological illustrations of the anticancer effects observed after $72 \mathrm{~h}$ of culturing OE21 esophageal cancer cells with $60 \mu \mathrm{M}$ each of compounds $\mathbf{1 , 2}$ and $\mathbf{4}$ and $80 \mu \mathrm{M}$ of compound 3. The cells that are dying and detaching from the culture substrate appear white and refringent: they are labeled as clusters of dying cells (CDC). The round and refringent cells are undergoing mitosis (M). 
and melanomas display high levels of intrinsic resistance to pro-apoptotic stimuli $(30,31)$. Dacarbazine, a close chemical analog of TMZ, represents the standard chemotherapy for melanoma patients $(18,27)$. Dacarbazine does not show higher growth inhibitory activity in vitro compared to temozolomide (27).

The data reported in Table I and Fig. 2 demonstrate the sensitivity of OE21 cells to the four studied alternethanoxins. Therefore, we used this cell line to grossly decipher the mechanisms of action by which these compounds inhibit OE21 cell proliferation. The white and refringent clusters of cells in Fig. 3 represent cells that are detaching from the culture support and dying. These dying cells (in clusters) must not be confounded with the single, round, refringent cells that are undergoing mitosis (Fig. 3). It appears that compound $\mathbf{4}$ is purely cytostatic, while compound $\mathbf{3}$ is cytotoxic; compounds $\mathbf{1}$ and $\mathbf{2}$ appear to be cytostatic, but signs of cytotoxicity are apparent after $72 \mathrm{~h}$ of culture. Thus, it seems that minor modifications of the chemical structure of alternethanoxin A (1), leading to compounds $\mathbf{3}$ and $\mathbf{4}$, can significantly modify its anticancer pharmacological properties (Figs. 2 and 3). These results suggest that the stereochemistry of the hemiacetalic hydroxy group at C-6, the phenolic hydroxy groups at C-1 and the presence of a furan ring joining rings $\mathrm{A}$ and $\mathrm{C}$ are not important chemical moieties for the in vitro anticancer activities of alternethanoxins. By contrast, modifications at C-6 and the phenolic hydroxy group at C-4 make it possible to change the cytotoxic activity of compound $\mathbf{3}$ to the cytostatic activity of compound 4 . The current data relating to in vitro anticancer activity agree with the preliminary SAR results obtained when assaying compounds 1-4 for their phytotoxicity on the host weedy plant Cirsium arvense (15).

In conclusion, the data from the present study are part of a larger story revealing that several natural compounds, including cardiotonic steroids $(17,26,27)$ and Kahalalide F $(37,38)$, have been recently identified as having the ability to kill apoptosis-resistant cancer cells through sustained proautophagic and/or lysosomal membrane permeabilization processes. Thus, it seems that the in vitro growth inhibitory activities displayed by compounds 1-4 in the present study, which are similar to those displayed by temozolomide, a compound used to combat cancers associated with dismal prognoses, and similar for 'apoptosis-resistant' and 'apoptosissensitive' cancer cells, are quite encouraging to enter into hemisyntheses intended to obtain alternethanoxin derivatives with higher activities against cancer cells that display intrinsic resistance to pro-apoptotic stimuli. We are currently pursuing these hemisyntheses and are attempting to decipher the exact mechanisms by which alternethanoxins are able to kill cancer cells.

\section{Acknowledgments}

We would like to thank the Italian Ministry University and Research (MIUR, contribution DISSPAPA N.207) and the Fonds National de la Recherche Scientifique (FNRS; Belgium). V.M. and F.L. are post-doctoral fellows at the FNRS, while R.K. is a Director of Research at the FNRS. M.B. holds a research grant from FRIA-FNRS.

\section{References}

1. Strobel GA: Phytotoxins. Annu Rev Biochem 51: 309-333, 1982.

2. Graniti A, Durbin RD and Ballio A: Phytotoxins and Plant Pathogenesis NATO ASI Series. Vol. 27. Springer-Verlag, Berlin, 1989

3. Ballio A and Graniti A: Phytotoxins and their involvement in plant disease. Experientia 47: 751-826, 1991.

4. Evidente A: Bioactive metabolites from phytopathogenic fungi and bacteria. In: Recent Research Developments in Phytochemistry. Pandalai SG (ed.) Research Signpost, Trivandrum, pp255-292, 1997.

5. Evidente A and Motta A: Phytotoxins from fungi, pathogenic for agrarian forestal and weedy plants. In: Bioactive Compounds from Natural Sources. Tringali C (ed.) Taylor \& Francis, London, pp473-525, 2001.

6. Evidente A: New fungal metabolites, as antifungal, herbicides and insecticides for biocontrol of agrarian plant pests. In: Potential \& Challenges; of the series: Comprehensive Bioactive Natural Products. Vol. 1, Gupta V (ed.) Studium Press, New Delhi, 2010.

7. Evidente A, Andolfi A and Cimmino A: The fungal phytotoxins for control Cirsium arvense and Sonchus arvensis. Pest Technol Rev (In press).

8. Evidente A, Andolfi A, Cimmino A and Abouzeid MA: Phytotoxins produced by fungi responsible of forestall plant disease. In: Sustainable Agriculture: Technology, Planning and Management. Salazar A and Rios I (eds.) Nova Science Publisher Inc., New-York (In press).

9. Evidente A: Chemical and biological characterization of toxins produced by weed pathogenic fungi as potential natural herbicides. In: Natural Products for Pest Management. ACS Symposium Series 927, Rimando AM and Duke SO (eds.) ACS Washington, pp62-75, 2006.

10. Evidente A and Abouzeid MA: Characterization of phytotoxins from phytopathogenic fungi and their potential use as herbicides. In: Integrated Crop Management. In: Handbook of Sustainable Weed Management, Singh HP, Batish DR and Kholi RK (eds.) The Haworth Press Inc., New-York, pp507-514, 2006.

11. Janssen T, Darro F, Petein M, Raviv G, Pasteels JL, Kiss R and Schulman CC: In vitro characterization of prolactin-induced effects on proliferation in the neoplastic LNCaP, DU145, and PC3 models of the human prostate. Cancer 77: 144-149, 1996.

12. Hayot C, Farinelle S, De Decker R, Decaestecker C, Darro F, Kiss $\mathrm{R}$ and van Damme M: In vitro pharmacological characterizations of the anti-angiogenic and anti-tumor cell migration properties mediated by microtubule-affecting drugs, with special emphasis on the organization of the actin cytoskeleton. Int J Oncol 21: 417-425, 2002.

13. Van Quaquebeke E, Mahieu T, Dumont P, Dewelle J, Ribaucour F, Simon G, Sauvage S, Gaussin JF, Tuti J, El Yazidi M, van Vynckt F, Mijatovic T, Lefranc F, Darro F and Kiss R: 2,2,2-Trichloro-N-(\{2-[2-(dimethylamino)ethyl]-1,3dihydro-1H-benzo[de]isoquinolin-5yl carbamoyl)acetamide (UNBS3157), a novel non-hematotoxic naphthalimide derivative with potent anti-tumor activity. J Med Chem 50: 4122-4134, 2007.

14. Lamoral-Theys D, Andolfi A, van Goietsenoven G, Cimmino A, Le Calvé B, Wauthoz N, Mégalizzi V, Gras T, Bruyère C, Dubois J, Mathieu V, Kornienko A, Kiss R and Evidente A: Lycorine, the main phenanthridine Amaryllidaceae alkaloid, exhibits significant antitumor activity in cancer cells that display resistance to proapoptotic stimuli: an investigation of structure-activity relationship and mechanistic insight. J Med Chem 52: 6244-6256, 2009.

15. Evidente A, Punzo B, Andolfi A, Beresyetskiy A and Motta A: Alternethanoxins A and B, polycyclic ethanones by Alternaria sonchi, potential mycoherbicide for Sonchus arvensis biocontrol. J Agric Food Chem 57: 6656-6660, 2009.

16. Lefranc F, Facchini V and Kiss R: Pro-autophagic drugs: a novel means to combat apoptosis-resistant cancers, with a special emphasis on glioblastomas. Oncologist 12: 1395-1403, 2007.

17. Lefranc F, Mijatovic T, Kondo Y, Sauvage S, Roland I, Krstic D, Vasic V, Gailly P, Kondo S, Blanco G and Kiss R: Targeting the alpha- 1 subunit of the sodium pump (the $\mathrm{Na}^{+} / \mathrm{K}^{+}$-ATPase) to combat glioblastoma cells. Neurosurgery 62: 211-222, 2008.

18. Mathieu V, Le Mercier M, De Neve N, Sauvage S, Gras T, Roland I, Lefranc F and Kiss R: Galectin-1 knockdown increases sensitvity to temozolomide in a B16F10 mouse metastatic melanoma model. J Invest Dermatol 127: 2399-2410, 2007 . 
19. Evidente A, Andolfi A, Vurro M, Zonno MC and Motta A: Cytochalasins Z1, Z2 and Z3, three 24-oxa[14]cytochalasans produced by Pyrenophora semeniperda. Phytochemistry 60: 45-53, 2002.

20. De Hauwer C, Camby I, Darro F, Migeotte I, Decaestecker C, Verbeek C, Danguy A, Pasteels JL, Brotchi J, Salmon I, van Ham P and Kiss R: Gastrin inhibits motility, decreases cell death levels and increases proliferation in human glioblastoma cell lines. J Neurobiol 37: 373-382, 1998.

21. Delbrouck C, Doyen I, Belot N, Decaestecker C, Ghanooni R, De Lavareille A, Kaltner H, Choufani G, Danguy A, Vandenhoven G, Gabius HJ, Hassid S and Kiss R: Galectin-1 is overexpressed in nasal polyps under budesonide and inhibits eosinophil migration. Lab Invest 82: 147-158, 2002.

22. Lamoral-Theys D, Pottier L, Kerff F, Dufrasne F, Proutière F, Wauthoz N, Neven P, Ingrassia L, van Antwerpen P, Lefranc F, Gelbcke M, Pirotte B, Kraus JL, Nève J, Kornienko A, Kiss R and Dubois J: Simple di- and trivanillates exhibit cytostatic properties toward cancer cells resistant to pro-apoptotic stimuli. Bioorg Med Chem (In press).

23. Huang P-L, Won S-J, Day S-H and Lin C-N: A cytotoxic acetophenone with a novel skeleton from Cynanchum taiwanianum. Helv Chim Acta 82: 1716-1720, 1999.

24. Saidou Balde E, Andolfi A, Bruyère C, Cimmino A, LamoralTheys D, Vurro M, van Damme M, Altomare C, Mathieu V, Kiss $\mathrm{R}$ and Evidente A: Investigations of fungal secondary metabolites with potential anticancer activity. J Nat Prod (In press).

25. Ingrassia L, Lefranc F, Dewelle J, Pottier L, Mathieu V, SpieglKreinecker S, Sauvage S, El Yazidi M, Dehoux M, Berger W, van Quaquebeke E and Kiss R: Structure-activity-relationship analysis of novel derivatives of narciclasine (an Amaryllidaceae Isocarbostyril alkaloid) as potential anti-cancer agents. J Med Chem 52: 1100-1114, 2009.

26. Mijatovic T, Mathieu V, Gaussin JF, De Neve N, Ribaucour F, van Quaquebeke E, Dumont P, Darro F and Kiss R: Cardenolideinduced lysosomal membrane permeabilization contributes therapeutic benefits in experimental human non-small-cell-lung cancers. Neoplasia 8: 402-412, 2006.

27. Mathieu V, Pirker C, Martin De Lassalle E, Vernier M, Mijatovic T, DeNeve N, Gaussin JF, Dehoux M, Lefranc F, Berger W and Kiss R: The sodium pumpa alpha-1 subunit: a disease progression-related target for metastatic melanoma treatment. J Cell Mol Med 9B: 3960-3972, 2009.
28. Branle F, Lefranc F, Camby I, Jeuken J, Geurts-Moespot A, Sprenger S, Sweep F, Kiss R and Salmon I: Evaluation of the efficiency of chemotherapy in in vivo orthotopic models of human glioma cells with and without $1 \mathrm{p} / 19 \mathrm{q}$ deletions and in C6 rat orthotopic allografts serving for the evaluation of surgery combined with chemotherapy. Cancer 95: 641-655, 2002.

29. Boyle P and Levin B: World Cancer Report 2008. World Health Organization. International Agency for Research on Cancer. Lyon, 2008.

30. Lefranc F, Brotchi J and Kiss R: Possible future issues in the treatment of glioblastomas, with a special emphasis on cell migration and the resistance of migrating glioblastoma cells to apoptosis. J Clin Oncol 23: 2411-2422, 2005.

31. Soengas MS and Lowe SW: Apoptosis and melanoma resistance. Oncogene 22: 3138-3151, 2003.

32. El Maalouf G, Le Tourneau C, Batty GN, Faivre S and Raymond E: Markers involved in resistance to cytotoxics and targeted therapeutics in pancreatic cancer. Cancer Treat Rev 35: $167-174,2009$.

33. Denlinger CE, Rundall BK and Jones DR: Modulation of antiapoptotic cell signaling pathways in non-small cell lung cancer: the role of NF-kappaB. Semin Thorac Cardiovasc Surg 16: 28-39, 2004.

34. D'Amico TA and Harpole DH Jr: Molecular biology of esophageal cancer. Chest Surg Clin North Am 10: 451-469, 2000.

35. Savage P, Stebbing J, Bower M and Crook T: Why does cytotoxic chemotherapy cure only some cancers? Nat Clin Pract Oncol 6: 43-52, 2009.

36. Wilson TR, Johnston PG and Longley DB: Anti-apoptotic mechanisms of drug resistance in cancer. Curr Cancer Drug Targets 9: 307-319, 2009.

37. Janmaat ML, Rodriguez JA, Jimero J, Kruyt FA and Giaccone G: Kahalalide $\mathrm{F}$ induces necrosis-like cell death that involves depletion of ErbB3 and inhibition of Akt signalling. Mol Pharmacol 68: 502-510, 2005.

38. Jimenez JC, Lopez-Macia A, Gracia C, Varon S, Carrascal M, Caba JM, Royo M, Francesch AM, Cuevas C, Giralt E and Alberico F: Structure-activity relationship of kahalalide F synthetic analogues. J Med Chem 51: 4920-4931, 2008. 